Provided for non-commercial research and education use. Not for reproduction, distribution or commercial use.

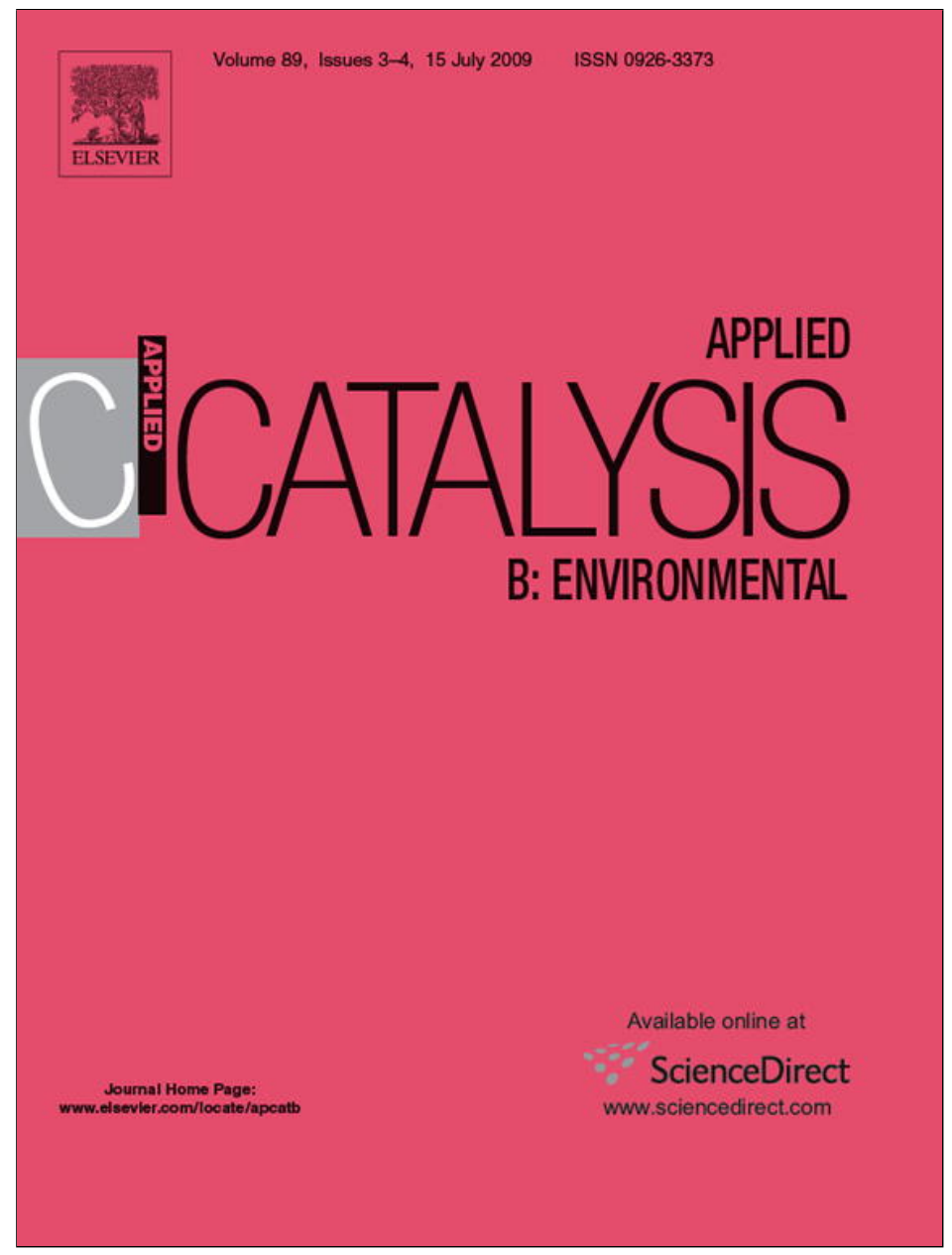

This article appeared in a journal published by Elsevier. The attached copy is furnished to the author for internal non-commercial research and education use, including for instruction at the authors institution and sharing with colleagues.

Other uses, including reproduction and distribution, or selling or licensing copies, or posting to personal, institutional or third party websites are prohibited.

In most cases authors are permitted to post their version of the article (e.g. in Word or Tex form) to their personal website or institutional repository. Authors requiring further information regarding Elsevier's archiving and manuscript policies are encouraged to visit:

http://www.elsevier.com/copyright 


\title{
Boosting $\mathrm{TiO}_{2}$-anatase antimicrobial activity: Polymer-oxide thin films
}

\author{
Anna Kubacka ${ }^{a}$, Manuel Ferrer ${ }^{a}$, María L. Cerrada ${ }^{b, *}$, Cristina Serrano $^{\mathrm{b}}$, Manuel Sánchez-Chaves ${ }^{\mathrm{b}}$, \\ Marta Fernández-García ${ }^{\mathrm{b}}$, Alicia de Andrés ${ }^{\mathrm{c}}$, Rafael J. Jiménez Riobóo ${ }^{\mathrm{c}}$, \\ Fernando Fernández-Martín ${ }^{\mathrm{d}}$, Marcos Fernández-García ${ }^{\mathrm{a}, * *}$ \\ ${ }^{a}$ Instituto de Catálisis y Petroleoquímica, Consejo Superior de Investigaciones Científicas, C/Marie Curie 2, 28049-Madrid, Spain \\ ${ }^{\mathrm{b}}$ Instituto de Ciencia y Tecnología de Polímeros, Consejo Superior de Investigaciones Científicas, C/Juan de la Cierva 3, 28006-Madrid, Spain \\ ' Instituto Ciencia de Materiales de Madrid, Consejo Superior de Investigaciones Científicas, C/Sor Juan Inés de la Cruz 3, 28049-Madrid, Spain \\ ${ }^{\mathrm{d}}$ Instituto del Frío, Consejo Superior de Investigaciones Científicas, C/José Antonio Novais 10, 28040-Madrid, Spain
}

\section{A R T I C L E I N F O}

\section{Article history:}

Received 21 November 2008

Received in revised form 24 December 2008

Accepted 11 January 2009

Available online 19 January 2009

\section{Keywords:}

Titania

Anatase

Nanocomposites

Thin films

Biocide

Germicide

Disinfection

\begin{abstract}
A B S T R A C T
$\mathrm{TiO}_{2}$ incorporation into an isotactic polypropylene (iPP) polymeric matrix was achieved via a straightforward and cost-effective melting process using laboratory-made nanometric anatase- $\mathrm{TiO}_{2}$ and an industrial polymer. The structural characteristics of the resulting nanocomposite thin films as a function of the inorganic component content were examined using wide and small angle X-ray scattering (WAXS/SAXS) and vibrational Raman spectroscopy. Electron scanning and transmission microscopy (SEM/TEM) studies were also performed to provide evidence of the nanometric dispersion of the oxide within the polymer matrix, showing the presence of average aggregates of ca. $80 \mathrm{~nm}$. $\mathrm{TiO}_{2}$ incorporation into the iPP renders self-sterilized nanocomposite films upon light excitation, the activity of which was tested against Gram negative ( $P$. aeruginosa) and positive (E. faecalis) bacteria. $\mathrm{TiO}_{2}$ displays maximum activity for a sample containing a $2 \mathrm{wt}$ \% of anatase- $\mathrm{TiO}_{2}$ irrespective of the microorganism nature. The antimicrobial activity of the nanocomposite films is significantly enhanced with respect to that of the oxide alone. This key fact is interpreted on physical basis with the help of a complete optical (UV-vis and photoluminescence) and electron paramagnetic resonance (EPR) characterization.
\end{abstract}

(c) 2009 Elsevier B.V. All rights reserved.

\section{Introduction}

The use of photocatalytic semiconductor oxides emerges as a successful technology to struggle against biological risks. $\mathrm{TiO}_{2^{-}}$ anatase is by far the most widely used photocatalyst, being a wide band-gap $(3.2 \mathrm{eV})$ semiconductor that under UV illumination generates energy-rich electron-hole pairs able to degrade cell components of microorganisms rendering innocuous products. Moreover, none weakness with respect to the microorganism nature (bacteria, virus, fungus, etc.) is nowadays known $[1,2]$. Consequently, its incorporation as a constituent in polymeric multicomponent materials could be a future alternative within goods packaging or biomedical fields, and would open the current playground for photocatalysis application. The important industrial success of isotactic polypropylene (iPP) and the wide range of its applications are basically due to the combination of outstanding physical properties, as the low density, the high tensile strength,

\footnotetext{
* Corresponding author.

** Corresponding author. Tel.: +34 9158554 75; fax: +34 915854760 . E-mail addresses: mlcerrada@ictp.csic.es (M.L. Cerrada), mfg@icp.csic.es (M. Fernández-García).
}

stiffness, hardness, thermal and good environmental resistance, ease of processability and recycling at a moderate cost [3]. The discovery of single-site metallocene catalysts has determined great improvements and advantages in polymerization and copolymerization of olefins [4,5]. Taking into account their good transparency, their aesthetic and mechanical properties, metallocene-catalyzed polypropylene resins provide a replacement for glass in some critical uses, as packaging of species keeping their organoleptic qualities, and for other plastics, as polyvinyl chloride in medical devices. These novel fields as well as the current general uses of PP, including automotive components, stationery and textiles (e.g. ropes, thermal underwear and carpets), among others, demand for improved polyolefins and, in particular, an important research area concerns the possibility of adding bactericidal properties to such polymeric matrices [6]. Modification of these polymer-based systems to prevent growth or reduce adhesion of detrimental microorganisms appears thus as a highly desired objective.

A point of relevance within the incorporation of the biocidal oxide into polymeric matrixes is the control of the $\mathrm{TiO}_{2}$ polymorphism ensuring the presence of the anatase form, the one with biocidal capability, as well as to control primary particle size in the nanometer range, a fact that would limit scattering 
events among other things [1,7]. The adequate handling of the morphological properties just mentioned would drive to the correct (UV) light-matter interaction and would ultimately lead to an optimized photoactivity in the elimination of microorganisms. This reasoning line implies, on the other hand, that the control of phase purity and morphological properties of the titania component would claim for the use of inorganic materials previously obtained to the nanocomposite preparation, ensuring in this way their physico-chemical properties. A side but important point to mention is the concomitant degradation of the polymer matrix by effect of the charge carriers; this has been proved to be limited by addition of small amounts of titania, typically below $5 \mathrm{wt} . \%$. Moreover, inclusion of titania in moderate amounts opens a new way to solve the general problem of disposal after completion of the polymer lifetime [7].

In this work, $\mathrm{iPP}^{-\mathrm{TiO}_{2}}$ nanoparticulated composite thin films are characterized and described in the context of the application of novel biocidal capabilities resulting from a nanometer anatase$\mathrm{TiO}_{2}$ component [8]. As well known, the addition of an inorganic modifier can alter iPP structure and crystallinity, affecting in this way physico-chemical properties and demanding for a complete structural characterization of the whole system [9]. Through a multitechnique approach, the study aims to show that adequate incorporation of $\mathrm{TiO}_{2}$ into a polymer-based nanocomposite film leads up to a powerful antimicrobial system, with a biocidal potential higher than that of the oxide alone. An efficient organoinorganic contact changes the nature of the $\mathrm{TiO}_{2}$ agent erasing the requirement of a close proximity with the pathogen, making the oxide in the nanocomposite a non-contact agent.

\section{Experimental}

The $\mathrm{TiO}_{2}$ component was prepared using a microemulsion synthetic route by addition of titanium (IV) isopropoxide (Aldrich) to an inverse emulsion containing an aqueous phase dispersed in $n$-heptane (Panreac), using Triton X-100 (Aldrich) as surfactant and 1-hexanol (Aldrich) as cosurfactant. The resulting mixture was stirred for $24 \mathrm{~h}$, centrifuged, decanted, rinsed under stirring five consecutive times with methanol (2), water (2) and acetone (1), in order to eliminate any portion from the organic and surfactant media, dried at $110{ }^{\circ} \mathrm{C}$ for $24 \mathrm{~h}$ and calcined at $500{ }^{\circ} \mathrm{C}$ for $2 \mathrm{~h}$. The synthesis gives pure anatase with a primary particle size of $10 \mathrm{~nm}$ [8]. A commercially available metallocene-catalyzed isotactic polypropylene, iPP (Basell Metocene X50081: melt flow index of $60 \mathrm{~g} / 10 \mathrm{~min}$ at $230^{\circ} \mathrm{C} / 2.16 \mathrm{~kg}$, ASTM D1238), meeting FDA requirements (Federal Regulations, 21 CFR 177.1520) for food contact, has been used as polymeric matrix in the preparation of iPP- $\mathrm{TiO}_{2}$ nanocomposites with different $\mathrm{TiO}_{2}$ nanoparticle contents: $0.5,1,2$ and 5 wt.\%, labeled as Ti0.5, Ti1, Ti2 and Ti5, respectively. The Licomont ${ }^{\circledR}$ AR 504 fine grain from Clariant (a polypropylene wax partially modified with maleic anhydride, PPgMA) was added as a compatibilizer agent to improve the interfacial adhesion between the iPP and $\mathrm{TiO}_{2}$. Use of PPgMA as an organic-inorganic compatibilizer is well established [10] and preliminary tests have evidenced that the best ratio of interfacial agent to be added is the $80 \mathrm{wt} . \%$ related to the $\mathrm{TiO}_{2}$ nanoparticles weight content at a given composition. These novel threecomponent materials were prepared through melt processing in an internal mixer with a volumetric capacity of $3 \mathrm{~cm}^{3}$ at $160{ }^{\circ} \mathrm{C}$ and at $60 \mathrm{rpm}$ for $5 \mathrm{~min}$. After blending and homogenization of the different components, specimens were obtained as films by compression molding in a Collin press between hot plates $\left(175^{\circ} \mathrm{C}\right)$ at a pressure of $1.5 \mathrm{MPa}$ for $5 \mathrm{~min}$. A quench from the melt to room temperature was applied to the different samples.

The crystal lattice characteristics of the nanocomposites were examined by wide angle X-ray scattering, WAXS, in the reflection mode at room temperature using a Rigaku Rotaflex RTP300 diffractometer connected to a computer having a Geiger counter and using a Ni-filtered $\mathrm{Cu} \mathrm{K} \alpha$ radiation. The diffraction scans were collected at a rate of $1^{\circ} / \mathrm{min}$ between $2 \theta$ values from $5^{\circ}$ to $30^{\circ}$, using a sampling rate of $1 \mathrm{~Hz}$. The goniometer was calibrated with a standard of silicon. The X-ray determinations of the degree of crystallinity were performed by subtraction of the corresponding amorphous component [11] comparing to the totally amorphous profile of an elastomeric PP sample. In addition, the transition associated with the melting process was investigated by real-time $\mathrm{X}$-ray diffraction experiments with synchrotron radiation. The synchrotron studies were performed in the soft-condensed matter beamline A2 at Hasylab (Hamburg, Germany), working at a wavelength of $0.150 \mathrm{~nm}$. Two different detectors were used in the setup. The first one, a MAR CCD detector, at a distance of $230 \mathrm{~cm}$ from the sample (covering the small angle scattering, SAXS, region) and the other, linear one, at around $17 \mathrm{~cm}$ from the sample and covering the approximate $2 \theta$ range from $11^{\circ}$ to $28^{\circ}$ (WAXS region). This WAXS detector was calibrated with the diffractions of a crystalline PET sample, and the SAXS detector, with the different orders of the long spacing of rat-tail cornea $(L=65 \mathrm{~nm})$. A heating rate of $8{ }^{\circ} \mathrm{C} / \mathrm{min}$ was employed, acquiring profiles every $15 \mathrm{~s}$. The two-dimensional X-ray patterns were processed with the FIT2D program (ESRF) and converted into one-dimensional arrays after normalization for the intensity of the primary beam and subtraction of the scattering of an empty sample.

Raman and photoluminescence measurements were performed at room temperature with different laser lines of an $\mathrm{Ar}^{+}-\mathrm{Kr}^{+}$laser: $333 \mathrm{~nm}+365 \mathrm{~nm}$, and $514 \mathrm{~nm}$. A home-made micro-Raman system was utilized; it consists on a Jobin-Yvon HR 460 monochromator, a $\mathrm{N}_{2}$ cooled CCD and a Kaiser Super-Notch-Plus filters (the latter used to suppress the elastic scattered light at $514 \mathrm{~nm}$ ). The excitation light was focused on the sample with an Olympus microscope (except for 333 and 365 nm UV laser lines) which is also used to collect the scattered light. Spectra are corrected by the instrumental function recorded with a calibrated white source and $\mathrm{CaF}_{2}$ pellet. For intensity measurements, Raman spectra are normalized using the total intensity of the $\mathrm{C}-\mathrm{H}$ rocking vibrations [12]. The EPR measurements were done with a Bruker ER200D spectrometer operating in the X-band and calibrated with a DPPH standard.

Scanning electron microscopy experiments for cross-section material analysis were carried out at room temperature in a XL30 ESEM PHILIPS equipment working at $25 \mathrm{kV}$. Samples were in situ cryofractured prior observations of the film cross-section. The samples were coated with gold-palladium (80:20) with a Sputter Coater (Polaron SC7640) working at $800 \mathrm{~V}$ and $5 \mathrm{~mA}$. Transmission electron microscopy experiments were carried out at room temperature in a $200 \mathrm{kV}$ JEM-2000 FX JEOL microscope. Samples were embedded in Spurr resine (low viscosity epoxi, cured at $60{ }^{\circ} \mathrm{C}$ for $48 \mathrm{~h})$ to obtain parallel cuts of the films surface in thin $(80 \mu \mathrm{m})$ sections by ultramicrotomy (Reichert-Jung Ultracut E), which were picked up on cooper grids and coated with a thin layer of carbon graphite (MED 010 Balzers evaporator) to improve heat conductivity.

The microorganisms used in this study included two clinical isolates: P. aeruginosa PAO clinical isolate PBCLOp11 from burn wound infections and $E$. faecalis clinical isolate brs 30 from human biliary, both classified according to 16S rRNA (unpublished). Bacterial cells were streaked from a glycerol stock onto a LB agar plate, grown overnight at $37{ }^{\circ} \mathrm{C}\left(P\right.$. aeruginosa: $\left.\mathrm{OD}_{600} \sim 6.0\right)$ (no antibiotics) and subsequently used. To study the antimicrobial activity of the films, a suspension containing $10 \mu \mathrm{l}$ of microbial cells (ca. $10^{9} \mathrm{cfu} \mathrm{ml}^{-1}$ ) suspended in $1 \mathrm{ml}$ broth solution was made as described elsewhere [13]. Aliquots of $1 \mathrm{ml}$ from these suspensions were added to a $4 \mathrm{ml}$ quartz cubic cell containing 
$1 \mathrm{ml}$ of sterilized water and the corresponding film under continuous stirring. The film-cell slurry was placed in the UV spectrometer chamber (UVIKON 930) and irradiated with a UV light of $280 \mathrm{~nm}$ for different periods of time. Care was put of using a sub-lethal, maximum radiation energy fluence of ca. $1 \mathrm{~kJ} \mathrm{~m}^{-2}$ throughout the study [14]. This was further confirmed with the help of blank tests. After irradiation and for different time intervals, aliquots of $100 \mu \mathrm{l}$ were transferred to a $10 \mathrm{ml}$ Luria-Bertani broth test tube. The order of cell dilution at this stage was $10^{-2}$. Loss of viability after each exposure time was determined by the viable count procedure on LB agar plates after serial dilution $\left(10^{-2}\right.$ to $10^{-5}$ ). All plates were incubated at $37^{\circ} \mathrm{C}$ for $24 \mathrm{~h}$ prior to enumeration. A minimum of three experimental runs was carried out to determine antimicrobial activity.

\section{Results and discussion}

The iPP matrix and all of the Tix nanocomposites are semicrystalline as their (reflection mode) WAXS profiles at room temperature, depicted in Fig. 1, indicate. These patterns display the five main diffractions characteristic of the $\alpha$ iPP modification $[15,16]$. Three different polymorphic modifications, $\alpha, \beta$ and $\gamma$, all sharing a threefold conformation [17-19], have been reported. In addition, a fast quenching of iPP leads to a phase of intermediate or mesomorphic order $[17,19,20]$. Concentrations of the $\gamma$ polymorph exceeding $80 \%$ have been found in metallocene-type polypropylenes prepared at conditions approaching those used in industrial processes [21]. However, no significant evidence of this $\gamma$ modification, through a peak at $19.7^{\circ}$ corresponding to its characteristic (1 117 ) reflection [22], is detected either in the iPP polymer or in the different Tix nanocomposites. This fact might be associated with the processing conditions imposed during the film preparation (e.g. cooling from the melt between water plates) since the proportion of $\gamma$ crystals is dependent on defects that interrupt isotactic sequences as well as on general crystallization conditions, diminishing at low crystallization temperatures [23] or with high cooling rates [24]. Estimation of the amorphous component content at room temperature, obtained from the totally amorphous profile of an elastomeric PP sample, allows determination of the crystallinity degree $\left(f_{\mathrm{c}}^{\mathrm{WAXS}}\right)$ from WAXS

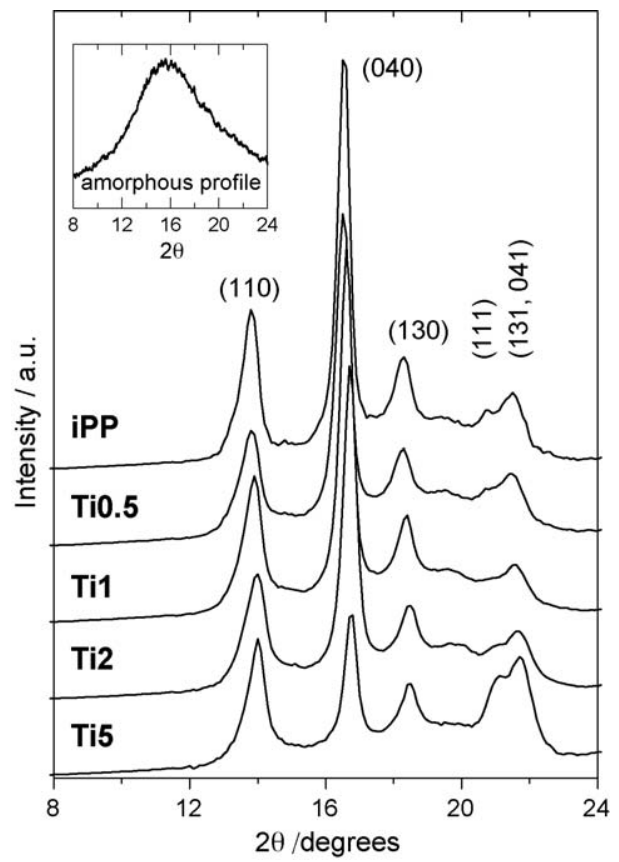

Fig. 1. WAXS profiles of different Tix nanocomposite thin films and iPP reference at room temperature. Inner plot: WAXS profile of amorphous polypropylene.
Table 1

Characteristics of the iPP crystalline phase for the different Tix nanocomposite thin films and for the neat iPP homopolymer: $f_{\mathrm{c}}^{\text {WAXS }}$ (crystallinity degree determined by WAXS at room temperature); $L^{\text {SAXS }}$ (long spacing estimated by SAXS at room temperature), and $l_{\mathrm{c}}$ (most probable crystal size calculated assuming a two-phase model: $\left.l_{\mathrm{c}}=L^{\mathrm{SAXS}} \cdot l_{\mathrm{c}}=L^{\text {SAXS }} \cdot f_{\mathrm{c}}^{\text {WAXS }}\right)$.

\begin{tabular}{lllc}
\hline Sample & $f_{\mathrm{c}}^{\text {WAXS }}$ & $L^{\text {SAXS }}(\mathrm{nm})$ & $l_{\mathrm{c}}(\mathrm{nm})$ \\
\hline iPP & 0.70 & 10.3 & 7.2 \\
Ti05 & 0.66 & 11.6 & 7.7 \\
Ti1 & 0.66 & 12.5 & 8.3 \\
Ti2 & 0.65 & 15.8 & 10.3 \\
Ti5 & 0.67 & 22.7 & 15.2 \\
\hline
\end{tabular}

$f_{\mathrm{c}}^{\text {WAXS }}$ standard error: $\pm 4 \% ; L$ and $l_{\mathrm{c}}$ standard error: $\pm 0.5 \mathrm{~nm}$.

experiments by simple subtraction. The $f_{\mathrm{c}}^{\text {WAXS }}$ values obtained are listed in Table 1 for the different films, rather constant values of crystallinity being observed independently of $\mathrm{TiO}_{2}$ incorporation. However, effect of $\mathrm{TiO}_{2}$ composition is mainly seen in relative variations of the intensity exhibited by several diffractions ( $\left(\begin{array}{ll}0 & 4\end{array}\right)$, (1 11 ) and (13 1, 041$)$ ) as deduced from Fig. 1.

The WAXS/SAXS structural characterization is summarized in Table 1 and indicates the relatively limited structural modification of the iPP matrix by effect of the anatase component presence; the single noticeable effect is the growth of the most probable crystal size $\left(l_{c}\right)$, particularly in the Ti5 film. The essential constancy of the iPP structural characteristics is also evidenced with Raman (Fig. 2) which, on the other hand, provides also information about the inorganic component state on the nanocomposites. As judged by
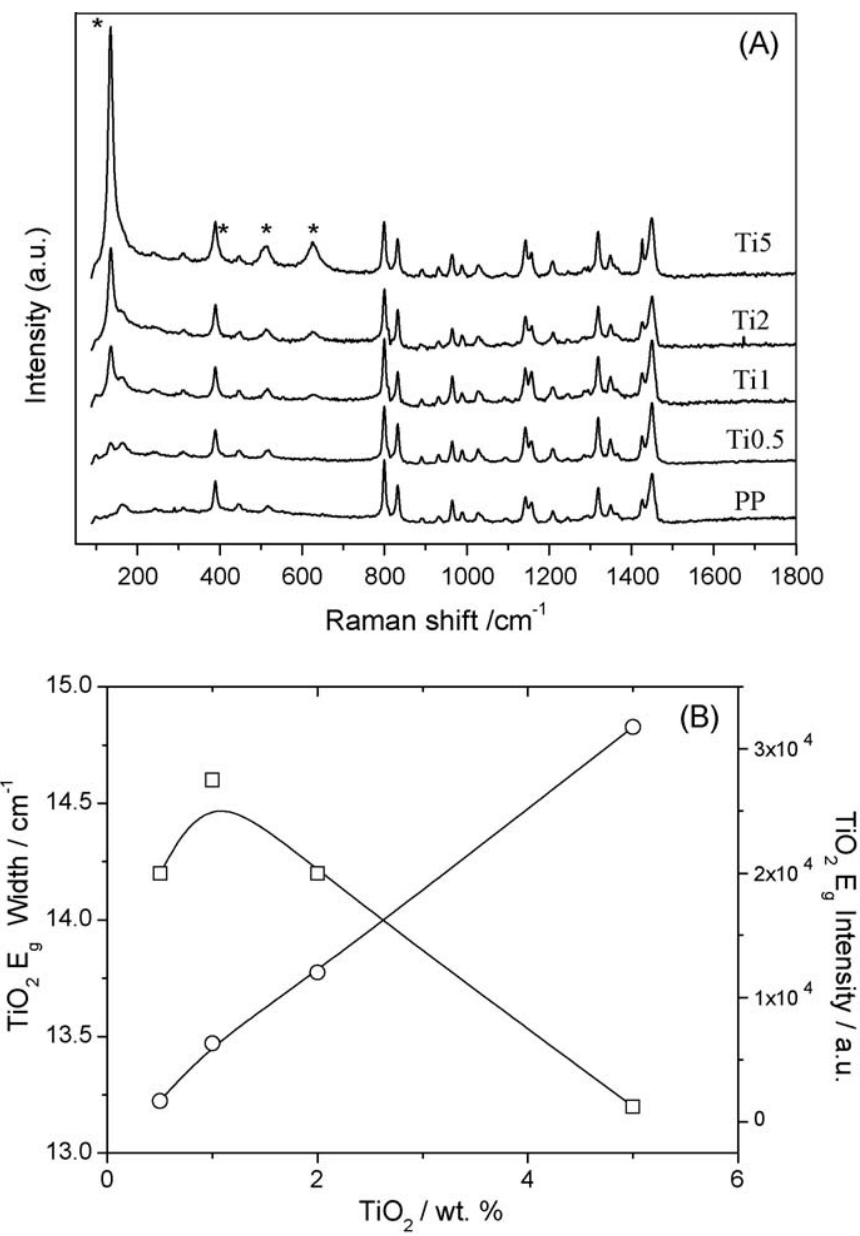

Fig. 2. Normalized Raman spectra of iPP (A), and width and intensity (B) of the anatase- $\mathrm{TiO}_{2} E_{\mathrm{g}}$ peak at $149 \mathrm{~cm}^{-1}$. Starts in plot A indicate anatase peaks. 

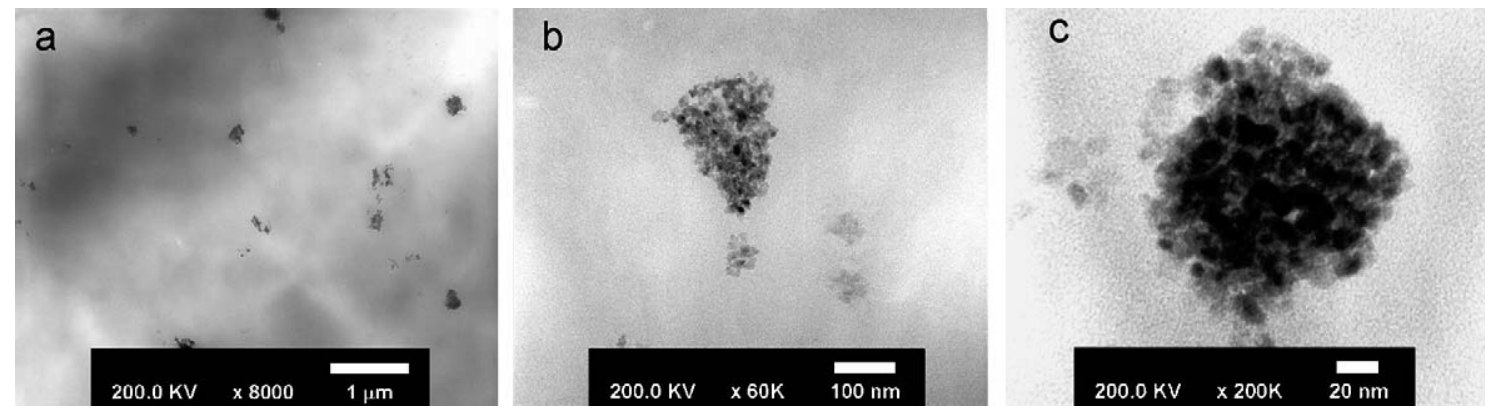

Fig. 3. TEM image of the Ti2 nanocomposite thin film and different details showing nanometer scale oxide agglomerates.

the invariant characteristics of the stronger $E_{\mathrm{g}}$ anatase peak at ca. $150 \mathrm{~cm}^{-1}$ (Fig. 2 bottom displays the peak width and intensity), the $\mathrm{TiO}_{2}$ component morphological characteristics seem to smoothly vary within the Tix series. The width informs about the expected constancy of the primary particle size of the inorganic component after the melt compounding while the linear behavior of the intensity would indicate that scattering events are similar in all samples, suggesting the probable similar aggregation state of the inorganic component. This latter was further studied with SEM; the cross-section SEM photographs (result not shown) showed no microsized aggregated nuclei, indicating that $\mathrm{TiO}_{2}$ nanoparticles have been highly dispersed within the iPP matrix and their practical absence at the surface of the material. This contrast with the microsized aggregates typically observed in other polyolefinbased nanocomposites with similar incorporations to the ones used in this study [25]. The absence of the oxide at the surface of the materials was further confirmed using the sensitive EPR technique with the assist of $\mathrm{O}_{2}$ as a probe molecule (see below).

The noticeable homogeneity of the Tix materials at the nanometer scale indicated by the SEM study is only possible because of the use of a coupling agent as well as the correct surface/size characteristics of the nano-oxide. To confirm this aspect, a TEM study of the Ti2 sample bulk (Fig. 3) was performed. In this case, the oxide is dispersed in the polymeric matrix exhibiting nanometer-scale aggregates ranging from 10 (the oxide primary particle size) to $200 \mathrm{~nm}$, with an average size (Feret diameter) [26] of $80 \mathrm{~nm}( \pm 20 \mathrm{~nm})$. Considering that the titania preparation makes use of an oxide previously calcined at high temperature $\left(500{ }^{\circ} \mathrm{C}\right)$ to ensure the exclusive presence of the anatase polymorph (e.g. absence of an amorphous contribution) and the strict control of its biocidal capabilities, the nanometric dispersion of the oxide reached for loadings below $5 \mathrm{wt}$ \% is significant, particularly with respect to micro-sized or bulk titania specimens [9c], or comparing with

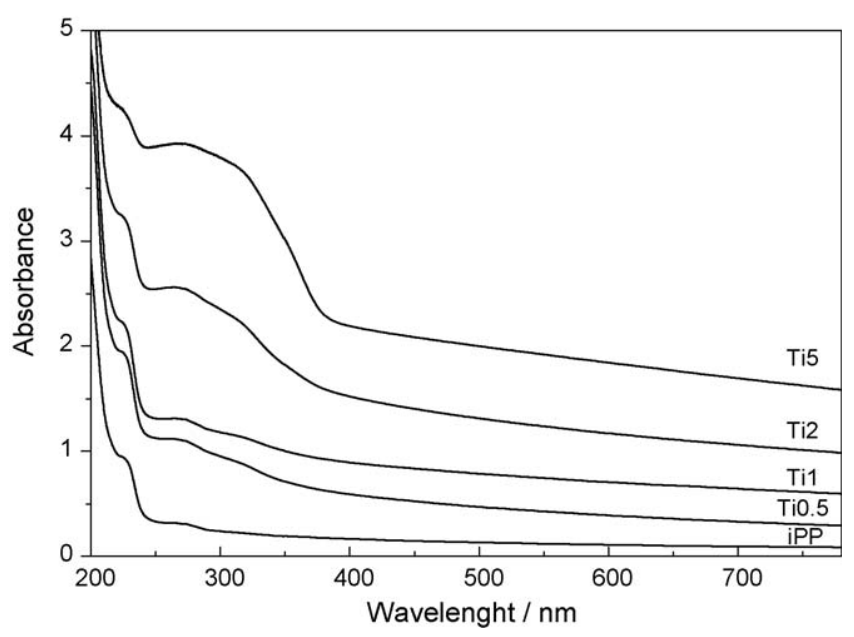

Fig. 4. UV-vis spectra of the neat iPP and Tix nanocomposite thin films. other inorganic components (clay, $\mathrm{SiO}_{2}$ ) introduced in polyolefins using a similar procedure (e.g. melting process) $[25,27]$. TEM images at high magnification (Fig. 3c) also suggest that both components are interwoven by penetration of the organic material into the porous network of the oxide, indicating the way a high interface area contact is obtained among components. The development of the component contact benefits from the preparation method here used and previously tested with other polymer matrixes [7].

As previously stated, the study of the UV excitation (UV-vis spectroscopy) and de-excitation (photoluminescence spectroscopy) of the materials corresponds to a key aspect to allow understanding of the system biocidal capabilities. The UV-vis absorption spectra of our $100 \pm 5 \mu \mathrm{m}$ films are shown in Fig. 4 . While the iPP spectrum displays a single feature at ca. $220 \mathrm{~nm}$ ascribed to cromophores (phenolic antioxidants and/or PP degradation products) coming from its industrial origin [28], the $\mathrm{TiO}_{2}$-related features appears barely visible for low loadings but become clearly visible for the Ti5 specimen. The onset of this broad feature occurs at ca. $380 \mathrm{~nm}$ and is characteristic of our anatase- $\mathrm{TiO}_{2}$ component bandgap energy [29]. In addition to this, the presence of the inorganic component progressively raises the background as the titania content of the nanocomposites increases. This energy behavior has been previously reported on PP-clay systems and ascribed to an enhancement of light scattering as the number of inorganic centers grows [30]. Upon UV light absorption with wavelength above ca. $250 \mathrm{~nm}$, creation of electron-hole pairs occurs mainly in the $\mathrm{TiO}_{2}$ component according to Fig. 4. Radiative relaxation of such charge carriers can be followed by photoluminescence spectroscopy and potentially informs of charge handling processes on the whole nanocomposite system [7b]. Fig. 5 plots the photoluminescence

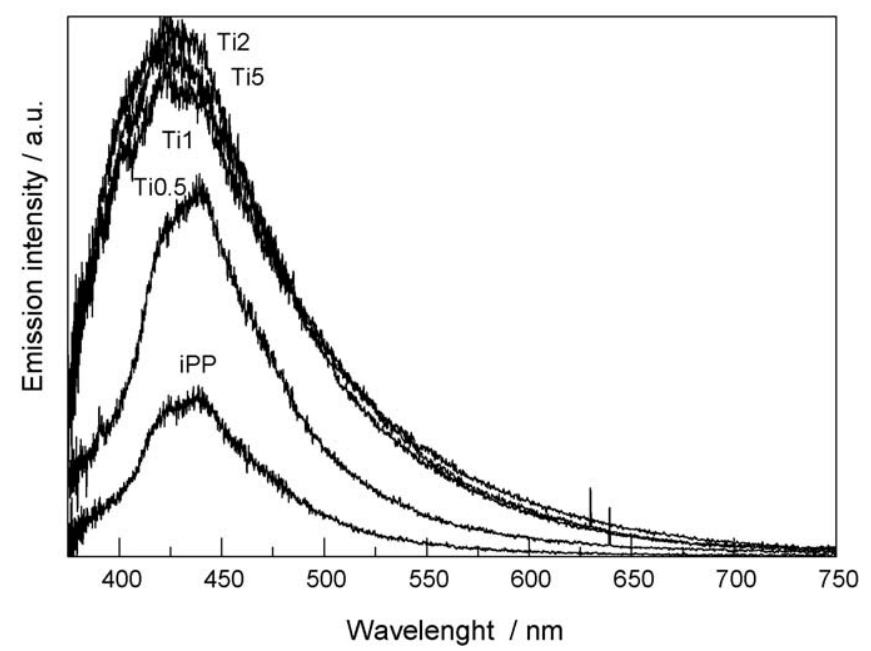

Fig. 5. Photoluminescence spectra of the neat iPP and Tix nanocomposite thin films. Excitation energy: $365 \mathrm{~nm}$. 
spectra of the samples showing strong similarities with that of the parent polymeric iPP matrix. As detailed elsewhere, these spectra are typical of the samples irrespective of the excitation wavelength, at least in the 230-380 $\mathrm{nm}$ range [30]. The iPP reference shows two broad features at ca. $425,440 \mathrm{~nm}$, the first characteristic of the PP matrix and the second associated with the presence of different chromophores (antioxidants, maleic acid residues, etc.) [30]. Inclusion of titania on the polymer enhances the radiative recombination pathway, typically at the expenses of the non-radiative de-excitation, but at $1 \mathrm{wt} . \%$ the presence of an additional broad contribution centered at ca. $390-400 \mathrm{~nm}$ becomes visible. As anatase- $\mathrm{TiO}_{2}$ is an indirect band-gap semiconductor, band edge luminescence is very difficult to be observed due to the inherent low probability of indirect transitions. In the case of nanometric anatase- $\mathrm{TiO}_{2}$, near band edge luminescence is attributed to oxygen vacancies with two trapped electrons, i.e. F centers [31]. These are likely related to surface states which are activated/enhanced only when the inorganic component is above $1 \mathrm{wt} . \%$. The interfacial inorganic-organic chemistry is somewhat modified to allow these to be detected above the cut-off limit of $1 \mathrm{wt} . \%$ while there are essentially undetectable for the Ti0.5 sample. No differences and a relatively constant behavior are encountered for Ti1, Ti2, and Ti5 samples in Fig. 5. So, above 1 wt.\%, the organicinorganic interface contact would allow charge transfer among components which, according to their band(s) gap and position, may include exciton (from the organic component) and/or hole (from the inorganic component) separation, leaving in this way holes into organic-like electronic states and electrons at the inorganic-like electronic states.

The analysis of charge carrier handling upon light excitation was completed with the help of EPR. The spectra of the films under vacuum (Ti5 is depicted as a representative example in Fig. 6a) show weak signals exclusively attributable to $\mathrm{TiO}_{2}$ species; an apparently axial shape displaying $g_{\perp} \approx 1.99$ and unresolved parallel component, ascribable to $\mathrm{Ti}^{3+}$ species, and another orthorhombic with $g_{1}=2.016-7, g_{2}=2.011-2 ; g_{3} \approx 2.002-4$, ascribable to trapped hole oxygen centers $\left(\mathrm{O}^{-}\right.$species $)$[32]. It is noticeable the lack of electron capture centers characteristic of the polymer component [33]. The null electron capture capability at the surface of the nanocomposite material was tested with oxygen. The absence of $\mathrm{O}_{2}{ }^{-}$radicals was noted in all conditions analyzed. These EPR results clearly indicate that the majority of electrons remain at the oxide component and that this component is dominantly at bulk positions, far from the system surface. Contrarily to this fact, the DMPO probe molecule provides pausible evidence for $\mathrm{OH}$ radical formation at the surface of the nanocomposite films. The characteristic 1:2:2:1 $(g=2.0056$, $a_{\mathrm{N}}=14.9 \mathrm{G}, a_{\mathrm{H}}=14.9 \mathrm{G}$ ) [34] signal is visible in Fig. 6b. The intensity behavior with time indicates multiple additions, within consecutive reactions, of $\mathrm{OH}$ radicals to DMPO molecules to yield diamagnetic species. To be brief, the joint optical/EPR analysis confirms that upon light excitation the organic/polymeric component located at the surface of the material handles holes primarily originated at the oxide. The exact hole oxide to polymer transfer mechanism is unknown; however, as the thermodynamic driving force of this phenomenon depends on both organic and inorganic conduction band end-ges, the managing of these two energy levels may increase the effectiveness of the transfer process. As a final effect, such charge carriers would be efficiently involved in the photo-killing of microorganisms for samples having a $\mathrm{TiO}_{2}$ content above $1 \mathrm{wt} . \%$. A side point concerns the degradation of the polymer by charge carrier attack, however previous results indicate that only after months of continuous use this would result in a significant effect [7].

Antimicrobial properties of the resulting nanocomposite films were tested against Gram negative $P$. aeruginosa and Gram positive E. faecalis (Fig. 7). We remark that both are antibiotic-resistance
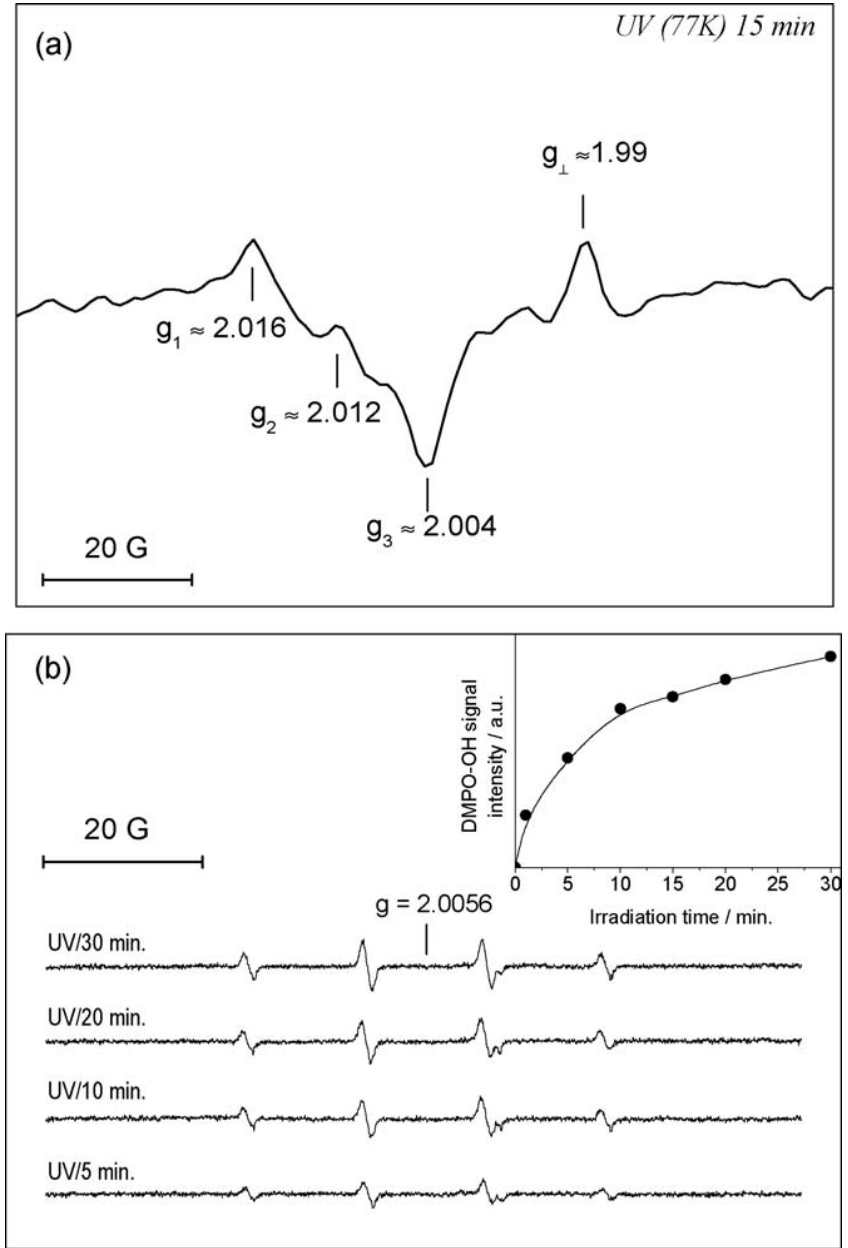

Fig. 6. EPR spectra of the PP-Ti5 sample; upon UV irradiation ( $15 \mathrm{~min}$ ) (a); and after DMPO-contact during UV irradiation (5, 10, 20 and $30 \mathrm{~min}$ ) (b). Inset in (b) shows the evolution of the DMPO-OH signal intensity as a function of irradiation time.

and clinically isolated strains, magnifying the interest of the present study. In these experiments, rather limited, sub-lethal energy fluences of ca. $1 \mathrm{~kJ} \mathrm{~m}^{-2}$ of a UV light $(280 \mathrm{~nm})$ were employed. The relatively innocuousness of the UV radiation is demonstrated by the blank/control experiments in presence of the iPP matrix; a maximum of ca. 1.0 log CFU-reduction (CFU: colony forming unit) is observed in our tests, in accordance with previous results $[7 a, 14]$. The nanocomposite films are complete inactive under dark conditions due to the practical absence of the oxide at the material surface. $\mathrm{TiO}_{2}$ performance appears highly efficient under UV-B and UV-A wavelengths (280-380 nm) [35] and results displayed in Fig. 7 provide conclusive evidence of this. Presence of the oxide on the nanocomposites has an important impact on the cell inactivation with respect to the blank test (measuring UV influence), increasing the initial velocity of elimination and further decreasing the final log-reduction at the end of the experiments. Some differences are however visible in the performance of the different Tix nanocomposite films with respect to the two microorganisms tested. In the case of $P$. aeruginosa a significant effect is already observed with the Ti0.5 samples while for $E$. faecalis the influence of the oxide on the biocidal activity is more gradual. The thicker wall of the Gram positive bacterium would probably help in rationalizing this result. Common to both experiments is that maximum performance is obtained using the Ti2 film. For that sample, almost complete cell inactivation of both microorganisms is reached, accounting for a log-reduction of near ca. 8 units. Note that the interaction with the polymer appears 

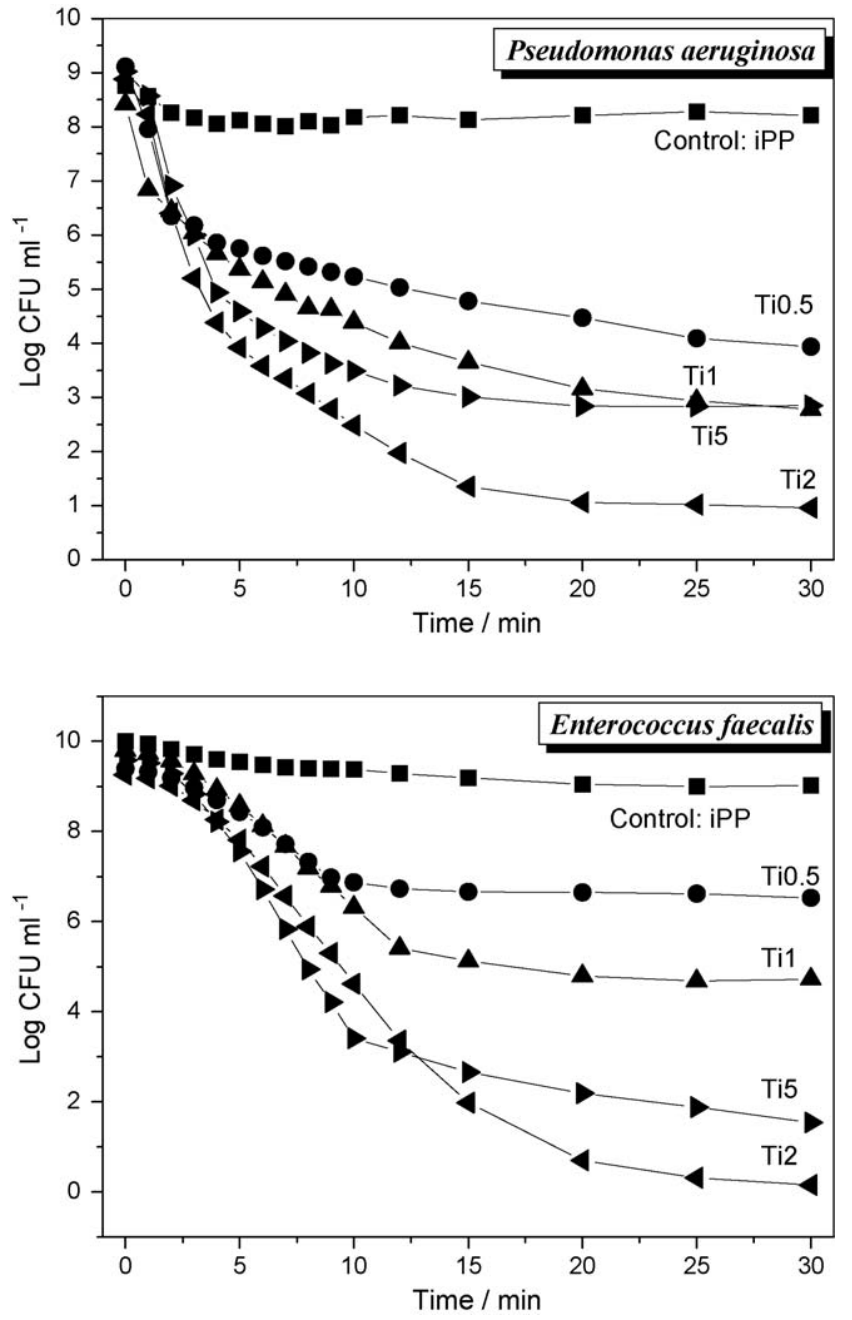

Fig. 7. Process come-up logarithmic reduction of microorganism population suspended in Luria-Bertani medium. Survival curves of $P$. Aeruginosa and E. faecalis as a function of the irradiation time for Tix and iPP control samples.

as a must in order to boost the biocidal action. We tested this by comparing with the oxide performance; a concentration of $8 \times 10^{-1} \mathrm{mg} \mathrm{mL}^{-1}$ is needed for a similar degree of cell inactivation. This value has to be compared with the nominal one (ca. $5 \times 10^{-2} \mathrm{mg} \mathrm{mL}^{-1}$ ) associated with the Ti2 test, which indicates an enhancement factor of 16 on the activity per titania weight basis. The oxide enhanced photokilling performance is a consequence of the above discussed charge handling properties of the nanocomposite, which makes the whole system biocidal and changes the oxide charge carrier behavior leading (from the oxide perspective) to a non-contact antimicrobial agent.

Comparison with other biocidal agents allows concluding that our systems display an unprecedented power for bacteria destruction. Concerning $P$. aeruginosa, our maximum ca. 8-9 log-reduction in $0.5 \mathrm{~h}$ can be compared with those observed using $\mathrm{TiO}_{2}$ either as a powder (Degussa P25; 3.5 log-reduction/0.67 h) [36] or supported on Plexiglas (5.4 log-reduction/1 h) [37] and ethylene-vinyl alcohol copolymer (EVOH; 8.3 log-reduction/0.5 h) [7a]. Comparison with reported results using Ag-based systems as commercial AgION coating stain steel (1.6 log-reduction/4 h) [38]; $\mathrm{AgBr}$ particles coating poly(vinyl pyridine)-NPVP (max. 4 logreduction) [39]; NO on silica (4 log-reduction/1.5 h) [40]; poly(alkylammonium) coatings on polyurethanes (4.4 log-reduction/ $0.5 \mathrm{~h}$ ) [41]; or simple chemicals like glutaraldehyde, formaldehyde, $\mathrm{H}_{2} \mathrm{O}_{2}$, phenol, cupric ascorbate or sodium hypochlorite (all below
6 log-reduction/0.5 h) [42] highlights the potential of our systems. As mentioned, the performance with $E$. faecalis is less studied but as a Gram positive bacterium has a thicker and more compact cell wall than the other microorganism of our study and thus is potentially more difficult to eliminate. Our result (ca. 8-9 logreduction $/ 0.5 \mathrm{~h}$ ) can be compared with water suspensions of $\mathrm{TiO}_{2}$ promoted with $\mathrm{Pt}(\mathrm{IV})$ salts (ca. 6 log-reduction/0.5 h) [43]; $\mathrm{TiO}_{2}$ supported on EVOH (6.3 log-reduction/0.5 h) [7a] or $\mathrm{TiO}_{2}-\mathrm{Ni}$ contains (2 log-reduction for extended period of times) [44]. Other biocides based on simple chemicals as trichlorosan on styrene-acetate copolymers (initial rate enhancement below 2 with respect to the polymer alone) [45]; organometallic complexes leading to oxygen radical formation (3.5 log-reduction/4 h) [46]; or UV-treated Nylon (1.8 log-reduction/6 h) [47] provide further support to our conclusion concerning the good performance of the nanocomposite films here described. The combined analysis of both microorganisms is thus illustrative of the biocidal potential of these films which showed a satisfactory performance if compared with most of the biocidal agents reported up to date.

\section{Conclusions}

This work describes a cost-effective preparation method of iPP$\mathrm{TiO}_{2}$ nanocomposite thin films with biocidal capability. Titania loadings between 0.5 and $5 \mathrm{wt} . \%$ were essayed. The complete characterization of the iPP- $\mathrm{TiO}_{2}$ nanocomposites provides evidence of the nanometric dispersion of the oxide component on the polymeric matrix, with average aggregates well below $100 \mathrm{~nm}$, and of the absence of significant changes in the structural properties of the polymeric matrix.

Optimal biocidal capabilities of the $\mathrm{iPP}-\mathrm{TiO}_{2}$ nanocomposite films were obtained with a $\mathrm{TiO}_{2}$ loading of $2 \mathrm{wt} . \%$, irrespective of the microorganism (Gram positive and negative bacteria) tested. This nanocomposite boosted the antimicrobial activity of the oxide component by efficiently managing charge carrier handling through the organic-inorganic interface, making in this way the whole system biocidal. As a result, the Ti2 nanocomposite thin film appears as a highly efficient novel iPP-modified thin film having advanced antimicrobial properties and a satisfactory overall performance if compared with current biocidal agents. These systems may find use for a wide variety of food packaging, biomedical, coating for "clean" solid surfaces or general disinfection applications.

\section{Acknowledgements}

Financial support from CSIC and MEC is acknowledged by Dr. A. Kubacka and Ms. C. Serrano for their I3P postdoctoral and FPU predoctoral grants, respectively. This work was supported by the CSIC under the projects PIF200580F0101, PIF200560F0102, PIF200560F103 and PIF200570F104. The synchrotron work was supported by the European Community - Research Infrastructure Action under the FP6 "Structuring the European Research Area" Programme (through the Integrated Infrastructure Initiative "Integrating Activity on Synchrotron and Free Electron Laser Science"), contract RII3-CT-2004-506008 (IA-SFS). We thank the collaboration of the Hasylab personnel in the soft-condensed matter beamline A2, especially Dr. S.S. Funari.

\section{References}

[1] O. Carp, C.L. Huisan, A. Reller, Prog. Solid State Chem. 32 (2004) 33.

[2] A.-G. Rincón, C. Pulgarín, Appl. Catal. B 49 (2004) 99.

[3] (a) P. Galli, G. Vecellio, Prog. Polym. Sci. 26 (2001) 1287

(b) P. Galli, G. Vecellio, J. Polym. Sci. Polym. Chem. Ed. 42 (2004) 396.

[4] H.H. Brintzinger, D. Fischer, R. Mulhaupt, B. Rieger, R.M. Waymouth, Angew Chem., Int. Ed. 34 (1995) 1143. 
[5] L. Resconi, L. Cavallo, A. Fait, F. Piemontesi, Chem. Rev. 100 (2000) 1253.

[6] P. Appendini, J.N. Hotchkiss, Innovative Food Sci. Technol. 3 (2002) 113.

[7] (a) A. Kubacka, C. Serrano, M. Ferrer, H. Lundsford, P. Bieleck, M.L. Cerrada, M. Fernández-García, M. Fernández-García, Nano Letters 7 (2007) 2529;

(b) A. Kubacka, M.L. Cerrada, C. Serrano, M. Fernández-García, M. Ferrer, M. Fernández-García, J. Nanosci. Nanotechnol. 8 (2008) 3241;

(c) M.L. Cerrada, C. Serrano, M. Sánchez-Chaves, M. Fernández-García, A. de Andrés, R.J. Jiménez-Riobóo, A. Kubacka, M. Ferrer, M. Fernández-García, Adv. Funct. Mater. 18 (2008) 1949.

[8] M. Fernández-García, X. Wang, C. Belver, J.C. Hanson, J.A. Rodríguez, J. Am. Chem. Soc. 129 (2007) 13604

[9] (a) X.S. Fan, J. Vinyl Add. Technol. 13 (2007) 65;

(b) P. Supaphol, P. Thanomkiat, J.Jonkesen, R. Dangtungee, Polym. Test. 26(2007)2; (c) D. García-López, O. Picazo, J.C. Marino, J.M. Pastor, Eur. Polym. J. 39 (2003) 945.

[10] D.N. Bikiaris, A. Vassilou, E. Pavlidou, G.P. Karayannidis, Eur. Polym. J. 41 (2005) 1965.

[11] S. Mansel, E. Pérez, R. Benavente, J.M. Pereña, A. Bello, W. Röll, R. Kirsten, S. Beck, H.-H. Brintzinger, Macromol. Chem. Phys. 200 (1999) 1292.

[12] A.S. Nielsen, D.N. Batcheler, R. Pryz, Polymer 43 (2002) 2671.

[13] M. Ferrer, J. Soliveri, F.J. Plou, N. López-Cortés, D. Reyes-Duarte, M. Christensen, J.L. Copa-Patiño, A. Ballesteros, Enzyme Microb. Technol. 36 (2005) 391.

[14] J. Jagger, Photochem. Photobiol. 34 (1981) 761.

[15] G. Natta, P. Corradini, Nuovo Cimento Suppl. 15 (1960) 40.

[16] A. Turner-Jones, J.M. Aizlewood, D.R. Becket, Makromol. Chem. 75 (1964) 134.

[17] S. Brückner, S.V. Meille, V. Petraccone, B. Pirozzi, Prog. Polym. Sci. 16 (1991) 361.

[18] B. Lotz, J.C. Wittmann, A.J. Lovinger, Polymer 37 (1996) 4979.

[19] P.J. Phillips, K. Mezghani, in: J.C. Salamone (Ed.), The Polymeric Materials Encyclopedia, vol. 9, CRC Press, Boca Raton, 1996, p. 6637.

[20] J. Arranz-Andrés, R. Benavente, E. Pérez, M.L. Cerrada, Polym. J. 35 (2003) 766

[21] R.G. Alamo, M.-H. Kim, M.J. Galante, J.R. Isasi, L. Mandelkern, Macromolecules 32 (1999) 4050.

[22] C. De Rosa, F. Auriemma, T. Circelli, Macromolecules 35 (2002) 3622.

[23] C. De Rosa, F. Aurienma, M. Paolillo, L. Resconi, I. Camurati, Macromolecules 38 (2005) 9143.

[24] E. Pérez, D. Zucchi, M.C. Sacchi, F. Forlini, A. Bello, Polymer 40 (1999) 675.
[25] D. Ma, Y.A. Akpalu, Y. Li, R.W. Siegel, L.S. Schadler, Polym. J. Sci. Part B: Polym. Phys. 43 (2005) 488.

[26] R.J. Matyi, L.H. Schartz, J.B. Butt, Catal. Rev. 29 (1987) 41.

[27] V. Vladimirov, C. Betcher, A. Vassilou, A. Papageonigiou, J. Bikiaris, Comp. Sci. Technol. 66 (2006) 2935.

[28] S. Morlat-Therias, B. Mailhot, D. Gonzales, J.L. Gardette, Chem. Mater. 16 (2004) 377.

[29] A. Kubacka, M. Ferrer, A. Martínez-Arias, M. Fernández-García, Appl. Catal. B 84 (2008) 87.

[30] M. Ambid, G. Teyssedre, D. Mary, C. Laurent, G.C. Montanari, IEEJ Trans. FM 126 (2006) 1097.

[31] N. Serpone, D. Lowless, A. Khairutdinov, J. Phys. Chem. 99 (1996) 16646.

[32] J.M. Coronado, A.J. Maira, J.C. Conesa, K.L. Yeung, V. Augugliaro, J. Soria, Langmuir 17 (2001) 5368.

[33] S. Esnouf, E. Balanzat, Polymer 48 (2007) 7531, and references therein

[34] D. Dvoranová, V. Brezová, M. Mazur, M.A. Malati, Appl. Catal. B 37 (2002) 91.

[35] A.K. Benabbou, Z. Derriche, C. Felix, C. Guillard, Appl. Catal. B 76 (2007) 257.

[36] J.A. Ibañez, M.I. Litter, R.A. Pizarro, J. Photochem. Photobiol. A 157 (2003) 81.

[37] K.P. Kuhn, I.F. Chaberny, K. Massholder, M. Stickler, V.W. Benz, H.-G. Sonnatg, L. Erdinger, Chemosphere 53 (2003) 71.

[38] M.M. Cowan, K.Z. Abshire, S.L. Houk, S.M. Evans, J. Ind. Microbiol. Biotechnol. 30 (2003) 102.

[39] V. Sambhry, M. Mecbridge, B.R. Peterson, A. Sen, J. Am. Chem. Soc. 128 (2006) 9796.

[40] E.M. Hetrick, J.H. Shin, N.A. Stasko, C.B. Johson, D.A. Wespe, E. Molmuhamedov, M.H. Schoenfisch, ACS Nano 2 (2008) 235.

[41] P. Kurt, L. Wood, D.E. Ohman, K.J. Wynne, Langmuir 23 (2007) 4719.

[42] J.C. Sagripanti, A. Bonifacio, J. AOAC Int. 83 (2000) 1415

[43] D. Mitoraj, A. Janczyk, M. Strus, G. Stochel, P.B. Heczko, W. Macyk, Photochem. Photobiol. Sci. 6 (2007) 642.

[44] Z. Zhi-hong, Y. Sakagami, T. Osaka, Chem. Lett. 90 (1997) 9.

[45] D. Chung, S.E. Papadakis, K.L. Yam, Int. J. Food Sci. Technol. 38 (2003) 165

[46] L. Villén, F. Majón, D. García-Resnadillo, G. Orellana, Appl. Catal. B 69 (2006) 1.

[47] A.E.H. Shearer, J.S. Park, D.G. Hoover, S.L. Hayne, Biotechnol. Bioeng. 67 (2000) 141. 